\title{
GASTROMEGALY FROM CHRONIC DUODENAL ULCER IN A CHILD
}

BY

\author{
REGINALD MILLER, M.D., F.R.C.P. \\ Physician, Paddington Green Children's Hospital, London.
}

The single case recorded here falls naturally into three chapters. (1) A previously healthy female baby began at the age of six months to suffer from vomiting which continued more or less up to the age of seven years. (2) At seven she showed extreme gastromegaly from obstruction to the evacuation of the stomach which operation discovered to be due to a chronic cicatrizing duodenal ulcer. Gastro-jejunostomy gave permanent relief from the symptoms of ulcer. (3) At the age of 28 her abdomen was opened for gall-stones and the scar of the old ulcer adherent to the head of the pancreas was seen.

\section{Case report.}

A.W., female, born 1900. Admitted on February 20th, 1907, aged 7 years, to the Paddington Green Children's Hospital, under the care of Dr. G. A. Sutherland, for vomiting, wasting and thirst.

The history was to the effect that the baby had been quite well until weaned at the age of six months.: Vomiting had then started and had been very troublesome for six months. It had then subsided to some extent but had never entirely stopped. She would vomit once or twice a week, and the vomit would be projectile in type, "coming all of a spurt as if she had been overloaded.' The vomiting was sufficient to retard progress considerably.

For 18 months before admission the vomiting had been more frequent and had led to the loss of much weight. It had occurred chiefly in the evening, especially on going to bed for the night, when all the food of the day would be brought up. The appetite had become extremely bad, but after being sick she would often ask for food. There had been no pain except immediately before the act of vomiting. There had been great thirst. The bowels had been usually constipated, but occasionally relaxed. At no time had blood been noted in the vomit or stools.

On admission, aged 7, she was very wasted and wizened, although not stunted in height. Her weight was only $27 \frac{1}{2} \mathrm{lb}$. She was frequently sick, and the vomits were large and projected with great force. On one occasion she vomited $52 \mathrm{oz}$. The vomit was frothy and contained mucus and fragmentary food. Gastric peristalsis was persistently visible in the three large waves typical of hypertrophy of the muscle of the stomach. No tumour could be felt, but splashing in the stomach was easily elicited. The bowels were constipated.

A course of gastric lavage, which brought away much mucus, combined with the use of small feeds, caused some improvement in the appetite, but there was a loss of weight of $2 \mathrm{lb}$. in a month.

On March 18th, 1907, Mr. F. F. Burghard operated and wrote the following note :- ' Gastrojejunostomy performed by posterior no-loop method. Much thickening of the first part of the duodenum, chiefly on the posterior aspect, but extending round five-sixths of the circumference near the pylorus. Many fine adhesions about the pylorus, the peritoneal coat of which was very vascular.'

By March 30th the child was on full diet, and she was discharged on April 17th, having gained $6 \mathrm{lb}$. weight since the operation.

Diagnosis : duodenal stenosia from cicatrizing duodenal ulcer dating from infancy. 
Arter-history. In May, 1929, I was able to get into touch with her. She was then aged 29 years, was 5 feet in height, and well nourished. She stated that after the operation in 1907 she had kept free of any abdominal symptoms until after she had turned 21 . She had then begun to suffer from flatulence and some pain after her meals, and these symptoms had gradually increased although at no time had she been sick. In August, 1928, she had had a severe attack of gall-st one colic with jaundice, and in the following month she had been admitted on this account to the West London Hospital, to the Medical Superintendent of which hospital I am indebted for the following facts :-

$\mathrm{X}$-ray examination of the alimentary tract showed that the old gastro-jejunostomy was functioning well. At operation an old ulcer in the region of the pylorus was found adherent to the head of the pancreas. The gall-bladder contained numerous small stones, and was removed. A pathological section of the wall of the gall-bladder showed inflammatory changes throughout. The patient was discharged in October, 1928.

In May, 1929, she stated that since the cholecystectomy the abdominal symptoms had disappeared. She still had the sensation which was habitual with her, that any large meal overfilled her, but this could easily be obviated by taking small meals at frequent intervals.

\section{Discussion.}

At each of the three periods of this case there are points of interest to be discussed. (1) Although there is now a considerable literature on the subject of infantile duodenal ulcer, it most of it dates, as Holt ${ }^{1}$ has observed, from 1908. The present case showed the symptoms of ulcer in 1900 and gastro-jejunostomy for the relief of the stenosis due to cicatrization was performed in 1907, a comparatively early date for this operation. We have therefore in this case, considered either as one of infantile ulcer or of gastro-jejunostomy, an exceptionally long after-history.

The first symptoms of duodenal ulcer did not appear until the sixth month of life. This is rather later than the majority of cases of this type. Palmer ${ }^{2}$, for instance, in 65 cases found that only 5 were over the age of five months. Adriance ${ }^{3}$ has recorded an example in a child of ten months. The onset of the symptoms occurred at the time of weaning, but this is probably no more than a coincidence, as it is not the rule to be able to trace any dietetic factor in the production of duodenal ulcer in infancy. There has been some discussion $\left(\right.$ Helmholz $^{4}$, Torday ${ }^{5}$ whether atrophic conditions of infancy predispose towards ulcer, but it seems certain that, as in this case, ulcer may develop suddenly in previously healthy babies. Ulcer of the duodenum has also been described (for instance, by Bloch ${ }^{6}$ ) as a complication of hypertrophic pyloric stenosis. The ulcer in infancy is usually immediately distal to the pylorus, as in the present case.

The projectile character of the vomiting, as seen in this case from the start, has becn noted by Holt and Palmer. It is presumably due to the spasm of the pylorus set up by the ulcer in its immediate neighbourhood. Visible gastric peristalsis and a palpable pyloric tumour are rare (Palmer). Although the vomiting in this case persisted for so long, no gross bleeding was noted at any time. This is in accord with Palmer's opinion that hæmatemesis and melæna are rarely seen in infantile cases ' until the end of the scene,' death usually occurring within 48 hours of such bleeding. 
The most unusual feature of the present case is its chronic course. The vomiting which started at the age of six months, never really subsided until the child was operated on at the age of seven years for duodenal stenosis. It is not easy to say at what age the cicatrization of the ulcer led to stenosis of the duodenum, but clearly from the age of $5 \frac{1}{2}$ years onwards the vomiting was due to the stenosis. This led to extreme gastromegaly and emaciation.

(2) At operation at the age of 7 years, the present case showed a chronic duodenal ulcer which had given rise to symptoms since the age of six months. Duodenal ulcers in children past the age of infancy are most commonly of tuberculous origin, as in the cases recorded by Gerdine and Helmholz ${ }^{7}$, and as such are of little clinical interest.

A chronic peptic ulcer in a child is certainly extremely rare. Proctor ${ }^{8}$ in 1925 reviewed the whole subject. He found that out of 6,664 cases of duodenal ulcer at the Mayo Clinic only one was in a child, which case he recorded ; but he noted that in 1,000 cases of duodenal ulcer in adults no less than 26 gave a history of symptoms dating back to childhood 'even to the age of four or five years.' Searching the literature for recorded cases of chronic peptic ulcer in children, Proctor was only able to collect 19 satisfactory and 2 questionable examples; and of these, three were instances of chronic duodenal ulcer (Bichat ${ }^{9}$, Alsberg ${ }^{10}$, and Palmer ${ }^{2}$ ). To these Proctor added the one instance from the Mayo Clinic already mentioned. Since Proctor's paper some other examples of duodenal ulcer in children over the age of infancy have come to light, although the chronicity of some of them is perhaps open to question. The list of these cases so far as I have been able to trace them is as follows :-

Bichat $^{9}$ (1910). Girl of 14 years showed perforated duodenal ulcer. Symptoms for 4 years previously. Recovery by operation.

Alsberg ${ }^{10}$ (1920). Girl of 2 years with sudden pain and bleeding. Operation showed duodenal ulcer scar near pylorus with adhesions to the liver. Recovered.

Palmer ${ }^{2}$ (1921). Boy of 6 months who had had symptoms almost from birth. Pyloroplasty followed 18 days later by gastro-jejunostomy. Recovered.

Proctor $^{8}$ (1925). Boy of 13 years : had had symptoms for 4 years. Old ulcer of duodenum extending round pylorus with great thickening and contraction. Gastro-enterostomy. 8 years later reported that he had kept quite well.

Carrick ${ }^{11}$ (1924). Boy of $10 \frac{1}{2}$ years. Symptoms for 2 years. Gastromegaly, visible peristalsis, stasis. $\mathrm{X}$-ray diagnosis.

Dickey ${ }^{12}$ (1926). Three cases diagnosed by skiagram, no operations. All boys. (1) Aged 9, with a history of pain 'ever since he could remember.' (2) Aged 11 $\frac{1}{2}$, with attacks of pain since 5 and melæna at 5 and 8 years. (3) Aged 8 years, with symptoms for 4 months.

Dickey $^{13}$ (1926). Boy of 13 years with intermittent epigastric pain for 1 year. Operation showed ulcer and diverticulum, both in the first part of the duodenum.

Paus ${ }^{14}$ (1926). Boy aged 14 years who had had the disease ' as long as he could remember.'

Pedrazzi ${ }^{15}(1927)$. Case diagnosed by skiagram. 11 years.

Pototschnig ${ }^{16}$ (1927). Perforated duodenal ulcer, not of infantile origin, in a child of

Flint ${ }^{17}$ (1927). Boy aged 12 years showed at operation a large mass surrounding a duodenal ulcer.

These cases indicate that should a child suffer from a chronic duodenaI ulcer it will probably have accuired it after the age of infancy. The present 
case, showing a chronic duodenal ulcer at seven years with a history dating back to the sixth month of life, seems in this particular to be unique. It may therefore be suggested that in such cases of infantile duodenal ulcer as survive healing is usually successful and complete.

The same point is brought out by the absence of scars in the duodenum in children. Gruber ${ }^{18}$, who examined with extraordinary care the duodenum in all autopsies he made for the five years 1906 to 1910, found in the age group 1-10 years ulcers in 10 cases, erosions in 7 cases, but no cicatrices. These last were not found at any age under the decade 30 to 40 years. Palmer also has noted how quickly and successfully healing takes place in the duodenal ulcer of infancy.

(3) No particular comment is necessary to display the interest in the lengthy after-history in the present case. This must be unique amongst recorded cases of infantile duodenal ulcer.

\section{Summary and conclusions.}

1. A case of duodenal ulcer arising at the age of six months is followed until the patient attained the age of 29 years.

2. Chronic duodenal ulcer is extremely rare in children of any age. Where it is found in older children it has not usually arisen from an ulcer originating in infancy. Similarly, scarring of the duodenum is of great rarity in children.

3. It is concluded that if an infant with duodenal ulcer survives the acute early period of the disease, healing of the ulcer is likely to be complete.

I am indebted to my friend, Dr. G. A. Sutherland, for his kind permission to make use of the notes of his case reported here.

\section{REFERENCES.}

1. Holt, L. E., Amer. J. Dis. Child., Chic., 1913, VI, 381.

2. Palmer, D. W., Ann. Surg., Philad., 1921, LXXIII, 545.

3. Adriance, V., Arch. Ped., N.Y., 1901, XVIII, 277.

4. Helmholz, H. F., Ibid., 1909, XXVI, 661.

5. Torday, F. v., Jahrb. f. Kinderh., Berlin, 1906, LXIII, 563.

6. Bloch, C. E., Ibid., 1907, LXV, 337, 477.

7. Gerdine, L., \& Helmholz, H. F., Amer. J. Dis. Child., Chic., 1915, X, 397.

8. Proctor, O. S., Surg. Gynec. Obst., Chic., 1925, XLI, 63.

9. Bichat, H., Rev. méd. de l'est., Nancy, 1910, XLII, 641.

10. Alsberg, J., Arch. f. Verdauungskr., Berlin, 1920-1, XXVII, 396.

11. Carrick, W. M., Brit. J. Radiol., Lond., 1924, XXIX, 411.

12. Dickey, L. B., Amer. J. Dis. Child., Chic., 1926, XXXII, 872.

13. Dickey, L. B., J. Amer. Med. Ass., Chic., 1926, LXXXVI, 815.

14. Paus, N., Acta Chir. Scand., Stockholm, 1926, LXI, 40.

15. Pedrazzi, C., Arch. di Radiol., Naples, 1927, III, 75.

16. Pototschnig, G., Arch. ital. di chir., Bologna, 1927, XVII, 508.

17. Flint, E. R., Proc. R. Soc. Med., Lond., 1926-7, XX, 649 (Sect. Su:g.), 41.

18. Gruber, G. B., München med. Wchnschr., München, 1911, LVIII, 1668. 